\title{
MiR-34b-3 and miR-449a inhibit malignant progression of nasopharyngeal carcinoma by targeting lactate dehydrogenase $\mathbf{A}$
}

\author{
Huiling Li ${ }^{1,2}$, Xiaoling $\mathrm{Li}^{2}$, Xiaolu Ge${ }^{2}$, Liqing $\mathrm{Jia}^{2}$, Zhezhe Zhang ${ }^{2}$, Renpeng Fang ${ }^{4}$, \\ Jing Yang ${ }^{2}$, Jianpin Liu ${ }^{3}$, Shuping Peng ${ }^{2}$, Ming Zhou ${ }^{2}$, Juanjuan Xiang ${ }^{2}$, Zhaoyang \\ Zeng $^{2}$, Wen Zhou ${ }^{2}$, Wei Xiong ${ }^{2}$, Gaoming Xiao ${ }^{1}$, Li Fang ${ }^{1}$, Gui-yuan Li ${ }^{1,2}$, Zheng Li ${ }^{1,2,3}$ \\ ${ }^{1}$ Hunan Cancer Hospital and The Affiliated Cancer Hospital of Xiangya School of Medicine, Central South University, Changsha, \\ China \\ ${ }^{2}$ The Key Laboratory of Carcinogenesis of The Chinese Ministry of Health and The Key Laboratory of Carcinogenesis and \\ Cancer Invasion of The Chinese Ministry of Education, Cancer Research Institute, Central South University, Changsha, China \\ ${ }^{3}$ High Resolution Mass Spectrometry Laboratory of Advanced Research Center, Central South University, Changsha, China \\ ${ }^{4}$ Xiangya School of Medicine, Central South University, Changsha, China
}

Correspondence to: Zheng Li, email: lizheng@csu.edu.cn

Keywords: nasopharyngeal carcinoma, miR-34b-3, miR449a, LC-MS/MS, lactate dehydrogenase A(LDHA)

Received: January 19, 2016

Accepted: July 06, 2016

Published: July 21, 2016

\section{ABSTRACT}

MicroRNA expression profiling assays have shown that miR-34b/c and miR-449a are down-regulated in nasopharyngeal carcinoma (NPC); however, the targets and functions of $\mathrm{miR}-34 \mathrm{~b} / \mathrm{c}$ and $\mathrm{miR}-449 \mathrm{a}$ in the pathologenesis of NPC remain elusive. In this study, we verified $\mathrm{miR}-34 \mathrm{~b} / \mathrm{c}$ and $\mathrm{miR}-449 \mathrm{a}$ were significantly reduced with the advance of NPC. Overexpression of miR-34b-3 and miR-449a suppressed the growth of NPC cells in culture and mouse tumor xenografts. Using tandem mass tags for quantitative labeling and LC-MS/MS analysis to investigate protein changes after restoring expression of $\mathrm{miR}-34 \mathrm{~b}-3,251$ proteins were found to be down-regulated after miR-34b-3 transfection. Through 3 replicate experiments, we found that miR-34b-3 regulated the expression of 15 potential targeted genes mainly clustered in the key enzymes of glycolysis metabolism, including lactate dehydrogenase A (LDHA). Further investigation revealed that miR-34b-3 and miR-449a negatively regulated LDHA by binding to the $3^{\prime}$ untranslated regions of LDHA. Furthermore, LDHA overexpression rescued the miR-34b-3 and miR-449a induced tumor inhibition effect in CNE2 cells. In addition, miR-34b-3 and miR-449a suppressed LDH activity and reduced LD content, which were directly induced by downregulation of the LDHA. Our findings suggest that miR-34b-3 and miR-449a suppress the development of NPC through regulation of glycolysis via targeting LDHA and may be potential therapeutic targets for the treatment of NPC.

\section{INTRODUCTION}

Nasopharyngeal carcinoma (NPC) is a malignant tumor with poor prognosis. Compared with Western Europe and USA, Southern China region has a high prevalence of 20-50 cases per 100,000 individuals [1]. The majority of NPC patients are diagnosed at late stages and $70 \%$ of patients present with cervical lymph node metastasis at first consultation [2]. It is thus important to identify and validate biomarkers for the early diagnosis of NPC.

MicroRNAs (miRNAs) have shown to affect the NPC progression as oncogenes or tumor suppressors
[3-7]. MicroRNAs (miRNAs) are short non-coding RNAs of 19-25 nucleotides and induce posttranscriptional silencing mainly by interacting with the 3'untranslated regions (3'UTRs) of target mRNAs [8-9]. A large body of evidence has shown that miRNAs exert an important role in tumorigenesis and drug resistance through the regulation of multiple biological processes including apoptosis, proliferation and metastasis of cancer cells [10-13]. Using a stem-loop RT-PCR or miRNA microarray assay respectively, our previous study and other four independent labs revealed that miR-34b/c and miR-449a are down-regulated in NPC tissues [14-18]. The miR-34 
family consists of miR-34a, miR-34b and miR-34c, which are directly regulated by p53 [19-21]. In mammalians, miR-34a is located on chromosome $1 \mathrm{p} 36$, while miR-34b and miR-34c are located at chromosome 11q23 and have a common primary transcript [22]. MiR-34b/c has tissue specific functions and different expression patterns in various cancers. Our miRNA microarray assay (GSE32906) [14] has shown that miR-34b/c, but not miR-34a is down-regulated in NPC. MiR-449a is located at 5q11.2 and shares a very similar "seed" sequence and a cohort of targets genes with miR-34b/c [23-26]. In the regulation of spermatogenesis, miR-34b/c and miR-449a have redundant function through targeting of the E2F- Rb pathway [27-28]. However, the precise function and molecular mechanisms of miR-34b/c and miR-449a in the initiation and progression of NPC remain unclear.

In this study we firstly examined the roles of $\mathrm{miR}-34 \mathrm{~b} / \mathrm{c}$ and miR-449a in the dynamic development of NPC. To clarify the mechanisms of miR-34b/c and miR-449a in the suppression function of NPC, we used tandem mass tags (TMT) isotope labeling technology and LC-MS/MS analysis to explore miR-34b-3 potential target genes. We demonstrated that miR-34b-3 regulated the expression of 15 potential targeted genes including 5 key enzymes in glycolysis metabolism pathway, including lactate dehydrogenase A (LDHA). LDHA promotes a metabolic switch to aerobic glycolysis (Warburg effect), and plays an oncogenic role in most cancers [29-36]. Our results suggest that miR-34b-3 and miR-449a suppress the development of NPC by regulating glycolysis via targeting LDHA.

\section{RESULTS}

\section{miR-34b/c cluster and miR-449a are down-regulated in NPC}

Our previous miRNA array analysis showed that miR-34b/c cluster and miR-449a have low expression in NPC [14]. Here, we further verified the expression levels of miR-34 cluster and miR-449a by RT-PCR in another cohort of NPC samples including 45 NPC tissues of different stages and 10 non-tumor nasopharyngeal epithelial. The clinic information of samples was shown in Supplementary Table S1 (Supplementary information). The expression levels of miR-34b/c cluster and miR-449a were significantly and gradually reduced with advancing stages of NPC, with the lowest expression at the latest stage IV (Figure 1, Upper line; $* P<0.05, * * P<0.01$; $* * * P<0.001)$, indicating gradual loss of miR-34b/c cluster and miR-449a expression with the progression of NPC. Compared with the immortalized normal nasopharynx epithelial NP69 cells, miR-34b/c cluster and miR-449a were also significantly down-regulated in NPC cell lines (Figure 1, Bottom line). However, the expression levels of miR-34a were unchanged in NPC tissues and cell lines when compared with non-cancerous nasopharyngeal epithelial tissues and NP69 cells (Figure 1). These data provided strong evidence that $\mathrm{miR}-34 \mathrm{~b} / \mathrm{c}$ cluster and miR-449a were downregulated in NPC. Since miR-34b-3 and miR-34c-3, miR-34c-5 and miR-449a have the same seed sequences, respectively (Supplementary Table S2), we selected miR-34b-3 and miR-449a as representatives to study the functions and molecular mechanisms at the following study.

\section{Overexpression of miR-34b-3 and miR-449a suppresses the growth of NPC cells in culture and mouse tumor xenografts}

To examine the function of miR-34b-3 or miR-449a, NPC cell lines CNE2 and 5-8F were transfected with miR-34b-3 or miR-449a mimics to restore their expression levels. Over-expression of miRNAs was verified by qRT-PCR (Supplementary Figure S1). MTT assay showed that miR-34b-3 and miR-449a overexpression significantly reduced the proliferation of CNE2 cells (Figure 2A, $* P<0.05)$. Similarly, the colony formation assays verified that miR-34b-3 and miR-449a overexpression resulted in a significantly lower number of colonies than control miRNA (Figure $2 \mathrm{~B}, * * * P<0.001)$. Additionally, the abilities of invasion of these transfected cells were measured using a transwell assay. Migrated stained cells were counted and statistically analyzed by GraphPad Prism 5 for three independent experiments. Cells transfected with either miR-34b-3 or miR-449a showed significantly reduced cell invasion (Figure $2 \mathrm{C} ; * * * P<0.001$ ). Finally, the migration ability of these transfected cells were measured using a wound-healing assay. The results demonstrated that both miR-34b-3 and miR-449a repressed cell motility. (Figure 2D; $* * P<0.01 ; * * * P<0.001$, data from three independent experiments). Similar results were obtained in NPC cell line 5-8F (Supplementary Figure S2). These results clearly demonstrated that overexpression of miR-34b-3 or miR-449a repressed cell proliferation, invasion and migration of NPC cells in vitro.

We next asked whether miR-34b-3 or miR-449a overexpression could suppress tumor growth in vivo. To this end, CNE2 cells transfected with miR-34b-3 or miR-449a mimics for $48 \mathrm{~h}$ were subcutaneously injected into nude mice and tumor formation and volume were monitored. The nude mice receiving cells overexpressing miR-34b-3 or miR-449a formed significantly smaller subcutaneous tumors than mice receiving cells transfected with control miRNA. Moreover, tumor volumes examined at different time points indicated that miR-34b-3 and 449a suppressed tumor growth in vivo (Figure 2E).

\section{TMT quantification labeled protein expression analysis of cells with miR-34b-3 overexpression}

To explore the potential target genes of miR-34b-3, we used tandem mass tags (TMT) for quantitative labeling and LC-MS/MS to analyze the different expression of proteins following miR-34b-3 overexpression. CNE2 cells 
were transiently transfected with $\mathrm{miR}-34 \mathrm{~b}-3$ mimics or negative controls. After $48 \mathrm{~h}$, proteins were extracted from cells and digested. Subsequently, peptides were labeled by TMTs Label Reagents (Thermo, Germany) and mixed to mass spectrometric analysis (Figure 3A). Through analysis of three biological triplicates, we found 251 proteins were down-regulated after ectopic miR-34b-3 expression with ratio-fold change $\leq 0.8$ and $\log 2$ fold change $\leq-0.3$ between miR-34b-3 and NC. Among these 251 proteins, 15 proteins were consistently down-regulated in all three experiments (Figure 3B and 3C). These 15 commonly down-regulated genes were further analyzed by Kyoto Encyclopedia of Genes and Genomes (KEGG). These potential target genes were found to be mainly involved in glycolytic pathways and pyruvate metabolism (Figure 3D). Among these 15 genes, LDHA, LDHB, PGK1 and PHGDH were predicted to have complementary sequences in their $3^{\prime} \mathrm{UTR}$ with miR34b/c or miR-449a by one or more Targetscan, Pictar, and miRanda databases. In particular, LDHA was predicted by all three databases. From LC-MS/MS analysis, 18 peptides including 8 unique peptides of LDHA were detected. Figure 3E showed examples of peptide precursor $\mathrm{m} / \mathrm{z}$ values and charge states, which were identified from the corresponding MS/MS spectrum. LDHA is a key enzyme in glycolysis that plays an oncogene role in the metabolism of tumor cells [29, 37-40]. Increased serum level of lactate dehydrogenase $(\mathrm{LDH})$ is a poor prognostic factor for NPC [41] and also predicts survival in NPC patients treated with palliative chemotherapy [42] or intensity-modulated radiotherapy [43]. Inhibition of LDHA by oxamate is an effective therapeutic strategy for treatment of NPC [44, 45]. Therefore, we focused on LDHA in the following study.

\section{LDHA is overexpressed in NPC tissues and cell lines}

To investigate the role of LDHA in the progression of NPC, we detected LDHA expression levels in 20 NPC and 4 non-tumor nasopharyngeal epithelial of paraffin embedded biopsies by immunohistochemistry (IHC). LDHA was overexpressed in NPC tissues (Figure 4A). The clinic information of samples was shown in Supplementary Table S3 (Supplementary information). Furthermore, we analyzed the mRNA expression level of LDHA in 31 NPC samples and 10 non-tumor nasopharyngeal epithelial tissues from GSE12452 database. The results demonstrated that the high mRNA level of LDHA expression was associated with NPC TNM stage (Figure 4B, $P<0.001$ ). Further evaluation of the expression levels of LDHA in NPC cell lines by Western blotting verified that LDHA was increased in all NPC cell lines compared with NP69 cells (Figure 4C). These results clearly demonstrated that LDHA was overexpressed in NPC.

\section{LDHA is a direct target of miR-34b/c and miR-449a}

To validate that LDHA is a direct target gene of miR34b-3 and miR-449a, CNE2 cells were transfected with same amount of miR-34b-3 or miR-449a mimics. After $48 \mathrm{~h}$, the total RNA and protein were extracted for analysis of LDHA mRNA and protein levels. RT-PCR analysis showed that miR-34b-3 and miR-449a overexpression significantly reduced LDHA mRNA level (Figure 5A; $* P<0.05 ; * * * P<0.001)$. Western blot analysis showed that the endogenous expression of LDHA protein substantially decreased after miR-34b-3 or miR-449a transfection (Figure 5B). These results indicated that miR-34b-3 and miR-449a over-expression inhibited the endogenous LDHA expression both at mRNA and protein levels.

Furthermore, we cloned the 3'UTR of LDHA downstream of the luciferase open reading frame including wild type or mutant type of miR-34b-3 and miR-449a binding sites. MiR-34b-3, miR-449a mimics or scrambled miRNA were cotransfected with the luciferase constructs. Luciferase activity was detected by DualGlo luciferase assay kit (Promega). The results showed significant decrease of luciferase activity in wild-type
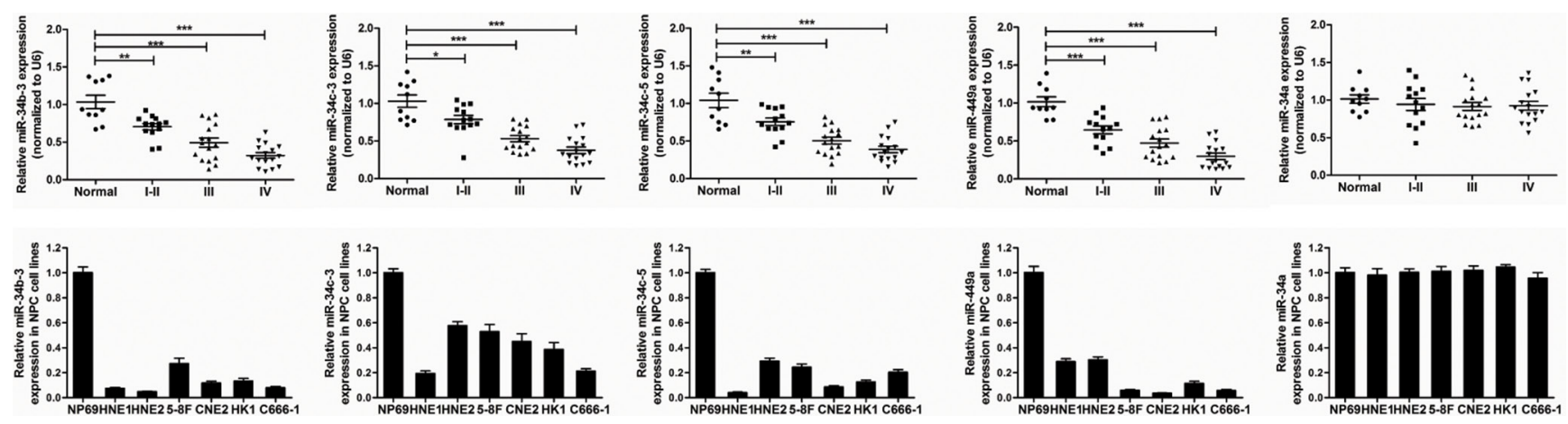

Figure 1: MiR-34b/c cluster and miR-449a are down-regulated in NPC samples and NPC cell lines. (Upper line) The real time RT-PCR determination of miR-34 cluster and miR-449a expression in different development stages of NPC $(n=45)$ compared with the non-tumor nasopharyngeal epithelial (normal, $n=10)$. I-II $(n=13)$, III $(n=16)$ or IV $(n=16)$ : NPC samples with clinical stage I-II, III or IV disease. Human U6 snRNA was used as an internal control and for normalization of the data. The data are shown as the mean \pm SD $\left({ }^{*} P<0.05 ; * * P<0.01 ; * * * P<0.001\right.$, ANOVA test). (Bottom line) The real time RT-PCR was performed to validate the expression of miR-34 cluster and miR-449a in the NPC cell lines and the immortalized normal nasopharynx epithelial NP69 cells. The expression of miRNAs was normalized to U6. 
vector but not in mutant vector after transfection of either miR-34b- 3 or miR-449a (Figure 5C; $* P<0.05$; $* * P<0.001)$. Furthermore, we found miR-34c-3, miR-34c-5 and miR-34b-5 had binding sites in 3'UTR of LDHA with sequences as predicted by miRanda. Western blot and RT-PCR analysis suggested that miRNAs replenish markedly repressed LDHA protein levels, but the mRNA level of LDHA was unchanged. The luciferase assay demonstrated that these three miRNAs also targeted 3'UTR of LDHA directly (Supplementary Figure S3), suggesting that miR-34c-3, miR-34c-5 and miR-34b-5 are involved in LDHA expression regulation. Collectively, these results clearly indicate that LDHA is a direct target of miR-34b/c cluster and miR-449a.

\section{MiR-34b-3 and miR-449a inhibit tumor progression in NPC by targeting LDHA to regulate glycolysis}

We then explored whether the tumor suppressor function of miR-34b-3 and miR-449a depends on LDHA expression. CNE2 cells were cotransfected with miR-34b-3 or miR-449a mimics and the pENTER-LDHA or control plasmid pENTER-3C (ve). Cells cotransfection of scrambled
A
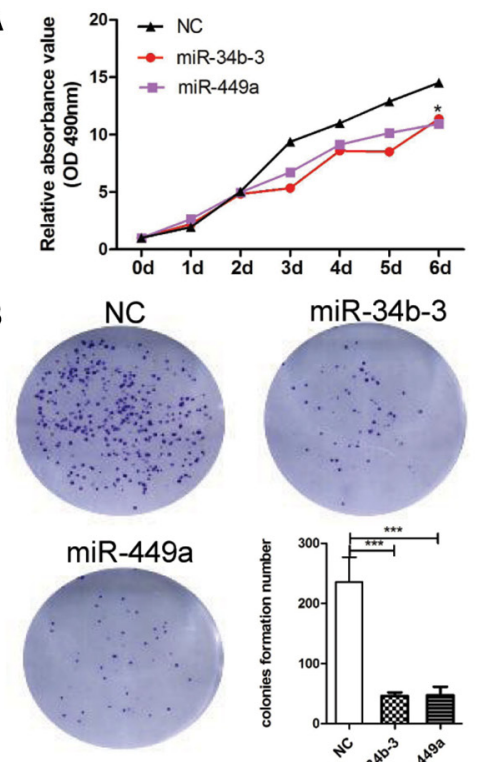

C

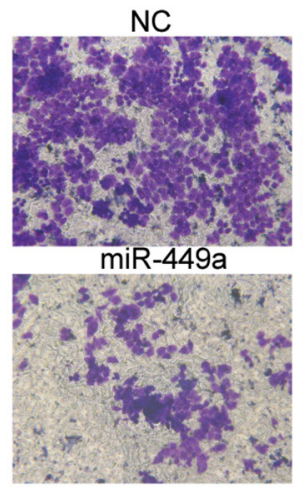

D

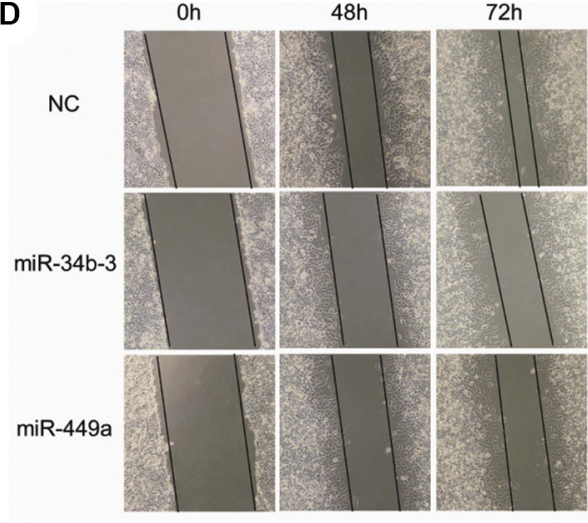

E

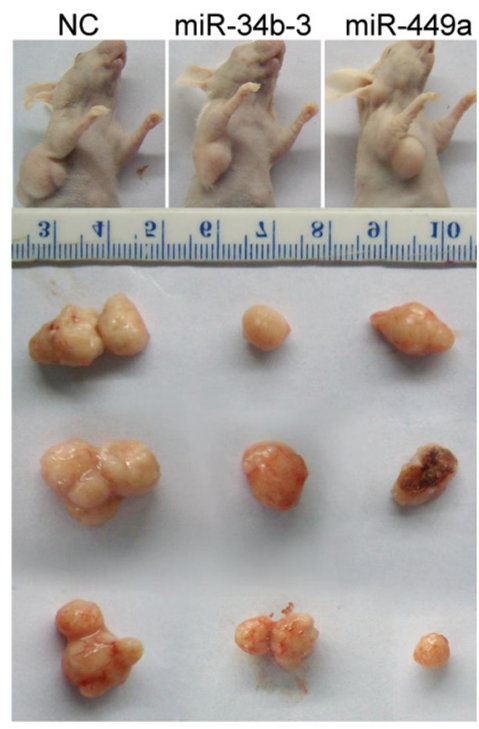

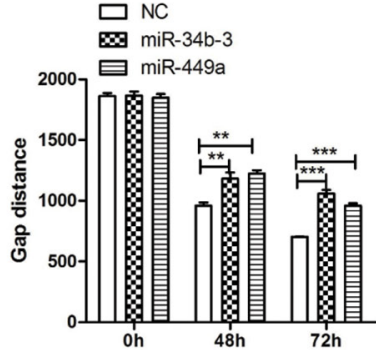

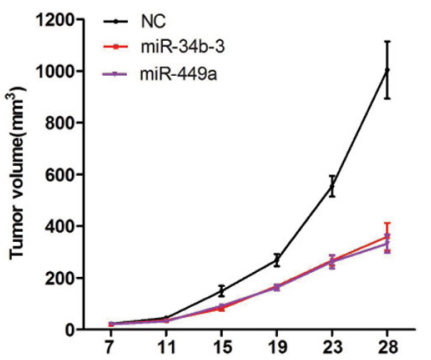

Figure 2: MiR-34b-3 and miR-449a play tumor suppressor roles in NPC. (A) miR-34b-3 and miR-449a suppressed tumor cell growth. NPC cells CNE2 was transfected with miR-34b-3 mimics, miR-449a mimics or scrambled miRNA (NC) and then subjected to MTT assay. The cell proliferation was measured at the indicated time points. Three independent experiments were performed. The data were shown as the mean $\pm \mathrm{SD}(* P<0.05)$. (B) Colony formation was inhibited in miR-34b-3 and miR-449a over expression CNE2 cells. A total of 1000 cells (CNE2) transfected with miR-34b-3 or miR-449a mimic or scrambled miRNA (NC) were seeded in six-well plates and allowed to grow for 10 days. The clone numbers were quantified. Three independent experiments were performed. The data were shown as the mean $\pm \mathrm{SD}(* P<0.05 ; * * * P<0.001)$. (C, D) The wound-healing assay and transwell assay showed that miR-34b-3 and miR-449a inhibited cell motility ability and invasion. The wound gap was measured and migrated stained cells were counted. Three independent experiments were performed and the data were shown as the mean $\pm \mathrm{SD}(* * P<0.01 ; * * * P<0.001)$. (E) miR-34b-3 and miR-449a suppressed tumor cell growth in vivo. Nude mice were subcutaneously injected with transfected CNE2 Cells $\left(1 \times 10^{6}\right)$. The tumors were measured every 4 days, and the growth curves were plotted for each group. The tumor volumes were estimated using the following formula: length $\times$ width $^{2} \times 0.52$ ( $n=5$ for each group, $* * * P<0.001$, ANOVA). All mice were sacrificed 28 days after inoculation and tumors were isolated and photographed at same time point. 
miRNA and pENTER-3C served as negative control (NC). Cells cotransfection of scrambled miRNA and pENTERLDHA served as positive control (LDHA). Western blot analysis showed that miR-34b-3 and miR-449a mediated decrease of LDHA expression was restored by pENTERLDHA in CNE2 cells (Supplementary Figure S4). Because pENTER-LDHA vector has $\mathrm{C}$ terminal Flag and His tag, the band included ectopic and endogenous LDHA expression. The MTT assay showed that ectopic overexpression of
LDHA significantly enhanced the proliferation of CNE2 cells and abolished the suppression of cell proliferation by either miR-34b-3 or miR-449a (Figure $6 \mathrm{~A}$; $* P<0.05$; $* * P$ $<0.001)$. Similarly, colony formation assay revealed that miR-34b-3 and miR-449a significantly suppressed colony formation compared with negative control, which was significantly prevented by LDHA overexpression (Figure 6B; $* P<0.05 ; * * P<0.001)$. Additionally, transwell migration assays showed that cells transfected with miR-34b-3 or miR-

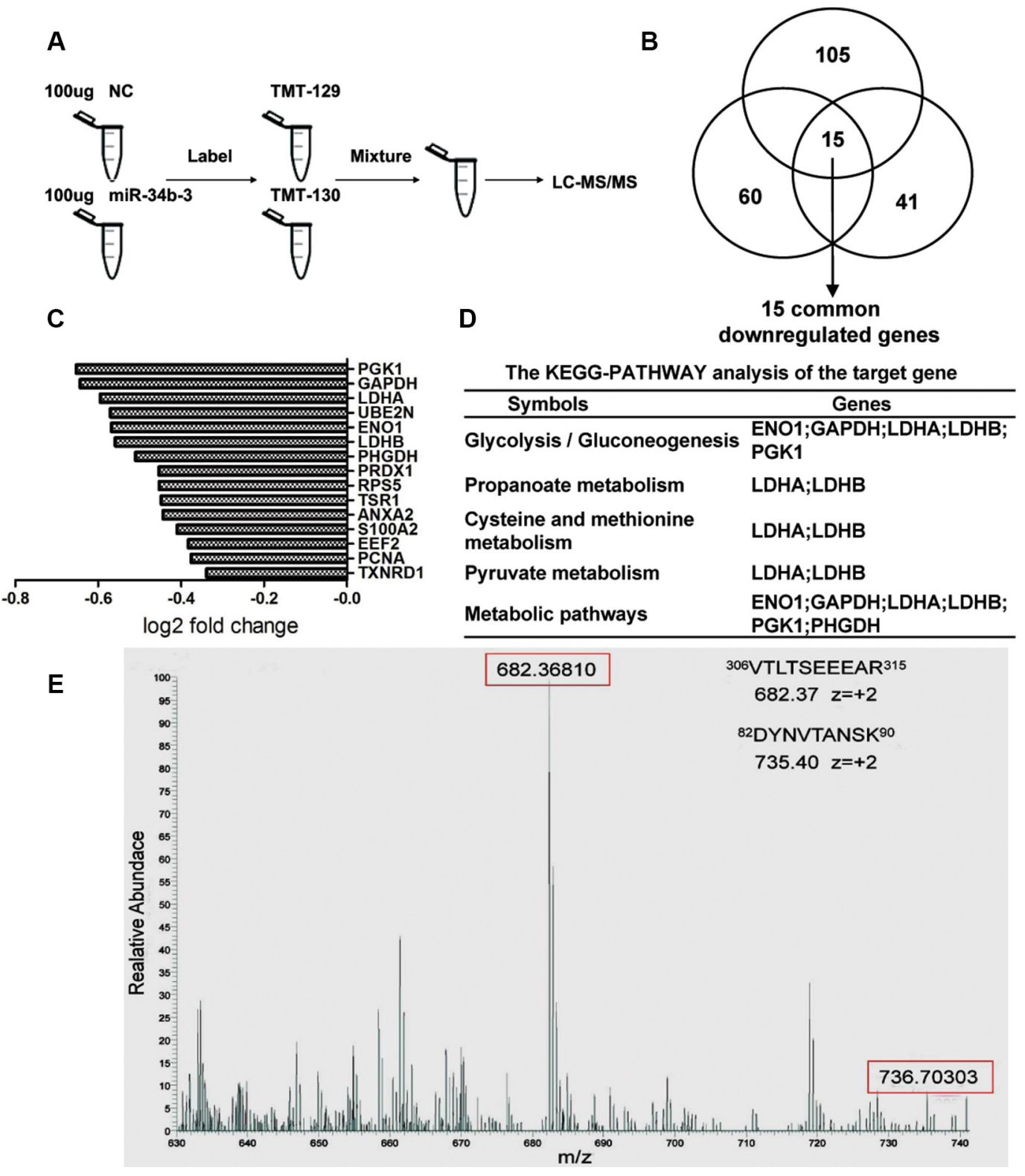

Figure 3: TMT quantification labeled protein expression analysis of cells with miR-34b-3 overexpression. (A) Samples and schematic outline of the TMT labeling and LC-MS/MS analysis. (B) The diagram of three independent experiments of protein expression changes after ectopic miR-34b-3 expression. Proteins with ratio-fold change $\leq 0.8$ and $\log 2$ fold change $\leq-0.3$ between miR-34b-3/NC were considered as potential regulated genes. (C) 15 common miR-34b-3 potential targets genes were detected by three biological replicate analysis. The fold changes difference for each gene were shown. (D) The potential target genes were analyzed by Kyoto Encyclopedia of Genes and Genomes (KEGG), the top 5 enrichment of biological processes were shown. (E) Examples of peptide precursor $\mathrm{m} / \mathrm{z}$ values and charge states which were identified from the corresponding MS/MS spectrum. LC-MS/MS spectra of precursor ions m/z 682.39 corresponding to residues 306-315 (VTLTSEEEAR) and m/z 735.40 corresponding to residues 82-90 (DYNVTANSK) of LDHA. 
449a mimics demonstrated significantly fewer migrated cells than the negative control, which was significantly recovered by LDHA overexpression (Figure $6 \mathrm{C},{ }^{*} P<0.05, * * P<0.01$, $* * * P<0.001)$. Collectively, these results demonstrated that LDHA overexpression rescued the suppressive effect of miR-34b-3 and miR-449a in CNE2 cells.

Given LDHA promotes L-lactate and NAD to pyruvate and NADH in the last step of glycolysis pathway, we next assessed whether miR-34b-3 and miR-449a regulated glycolysis in NPC cells through LDHA. CNE2 cells were transfected with miR-34b-3 or miR-449a mimics, and respectively cotransfected with pENTERLDHA. Subsequently, cell supernatants at $0 \mathrm{~h}$ and $24 \mathrm{~h}$ were collected and tested for the levels of lactic acid (LD) and lactic dehydrogenase (LDH). The results demonstrated that miR-34b-3 or miR-449a significantly decreased LD content and suppressed LDH activity when compared with negative control, whereas LDHA over-expression rescued the suppressive effect of miR-34b-3 and miR-449a (Figure 6D; $* P<0.05 ; * * P<0.01 ; * * * P<0.001$, data from three independent experiments). These results suggest that miR-34b-3 and miR-449a execute tumor suppressor gene function in NPC partly due to inhibition of glycolysis by down-regulating LDHA.

\section{DISCUSSION}

In this study, we showed that the expression levels of $\mathrm{miR}-34 \mathrm{~b} / \mathrm{c}$ cluster and miR-449a were significantly and gradually reduced with advancing stages of NPC, with the lowest expression at stage IV. Consequently, overexpression of miR-34b-3 and miR-449a suppressed the growth of NPC cells in culture and mouse tumor xenografts. Further tandem mass tags isotope labeling and LC-MS/MS analysis revealed that miR-34b/c and miR-449a regulated the expression of 15 potential targeted genes, mainly clustered in key enzymes of glycolysis metabolism, including LDHA. In addition, we found that LDHA was a direct target of miR-34b/c cluster and miR-449a and was overexpressed in NPC. Furthermore, ectopic overexpression of LDHA significantly abolished the suppression of the proliferation, invasion and migration of CNE2 cells by miR-34b-3 or miR-449a. Importantly, miR-34b-3 or miR-449a significantly decreased LD content and suppressed LDH activity, which was restored by ectopic overexpression of LDHA.

From meta-analysis, miR-34a, miR-34b and miR-34c are dysregulated simultaneously in most cancers, such as non-small cell lung cancer, endometrial carcinoma,

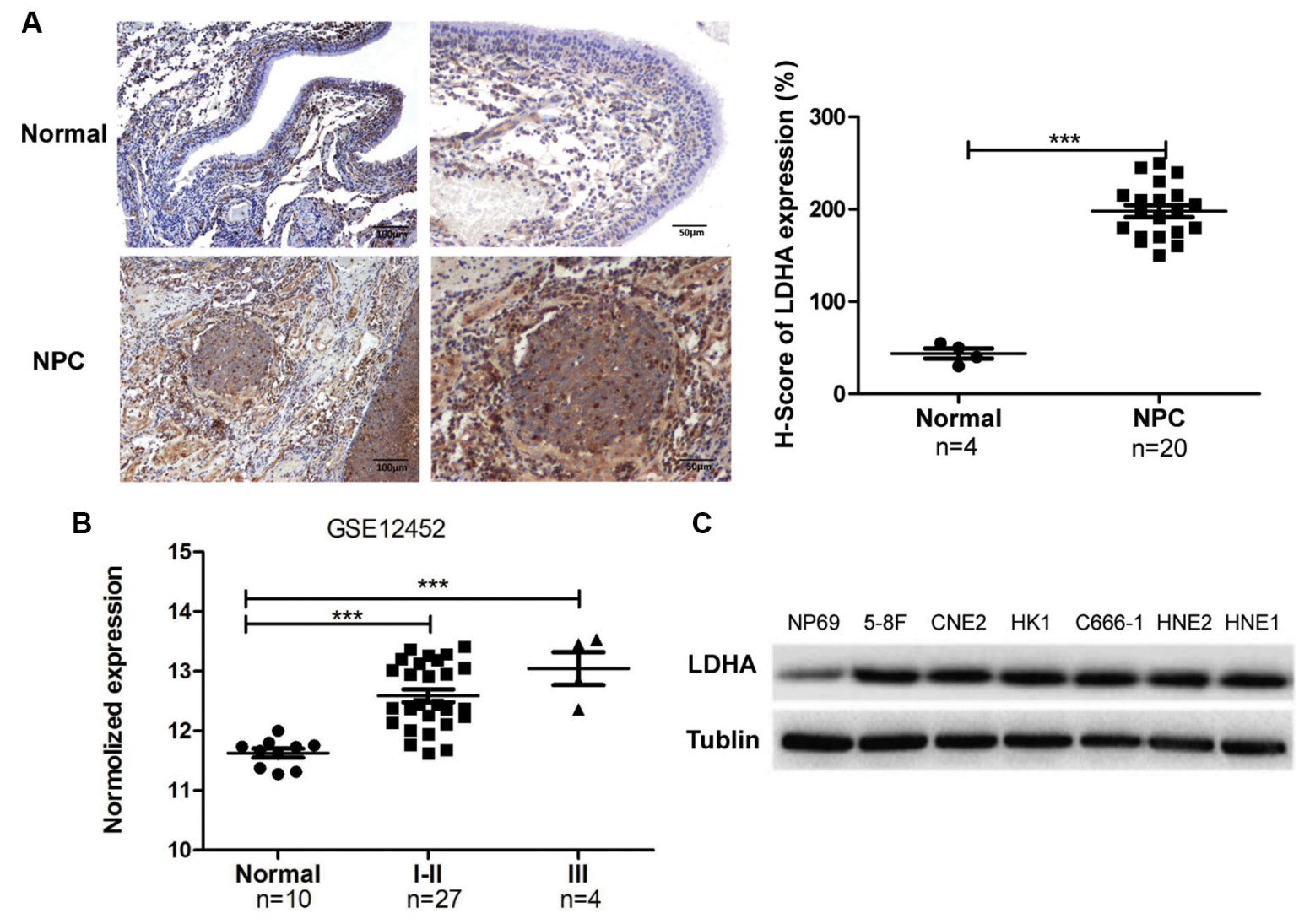

Figure 4: LDHA is overexpressed in NPC tissues and cell lines. (A) IHC analysis of LDHA protein expression in NPC and nontumor nasopharyngeal epithelial tissues (normal). Scale bars, $100 \mu \mathrm{m}$ and $50 \mu \mathrm{m}$. Representative images are shown (100 X and $200 \mathrm{X}$ ). LDHA expression levels was evaluated in a semiquantitative manner H-score. Each data point corresponds to the LDHA H-score of an individual tissue (***P<0.001). (B) LDHA mRNA expression in different development stages of NPC in the GSE12452 dataset. Normal: non-tumor nasopharyngeal epithelial tissues; I-II and III: NPC samples with clinical stage I-II or III disease (***P<0.001). (C) Expression of LDHA was detected by Western blotting in NPC cell lines and immortalized normal nasopharynx epithelial NP69 cells. 
colorectal cancer, ovarian carcinoma, osteosarcoma [46]. In normal human tissues, miR-34a is universally expressed in most tissues [47]. On the contrary, miR-34b/c is mainly expressed in lung, ovary, testes, and trachea [48], which may explain the obvious reduction of miR-34b/c but not miR-34a in NPC. MiR-449 cluster have very similar sequences and secondary structures belonging to the miR-34 family. Indeed, miR-449a has the same tissue distribution as miR-34b/c and they form a functionally related miRNA family. The double knock out mice of miR-34b/c and miR-449 show basal forebrain structures, absence of motile cilia in trachea and oviducts, and severe disruption of spermatogenesis, but no spontaneous tumor formation [49]. In this study, we found that loss of $\mathrm{miR}-34 \mathrm{~b} / \mathrm{c}$ and $\mathrm{miR}-449 \mathrm{a}$ was related with the progression of NPC, and overexpression of miR-34b/c and miR-449a inhibited the proliferation, migration and invasion of NPC cells in vitro and tumor size in vivo. These data suggest an important role for miR-34b/c and miR-449a in the suppression of the tumorigenesis of NPC.

To explore the molecular mechanisms of miR-34b/c and miR-449a as anti-oncogene in NPC, we used quantitative proteomics to find the direct targets of $\mathrm{miR}-34 \mathrm{~b} / \mathrm{c}$ and miR-449a. Peptides obtained from different experimental conditions are labeled with TMT labeling isobaric mass tags and mixed together. All isobaric mass tags have the same molecular weight in MS1 full mass spectra but produce distinct reporter ions after MS2 that permits peptide quantitation $[50,51]$. The relative abundance of a given peptide in each experimental condition can be determined by direct comparison of the reporter ion signal intensities. We compared the differential
A

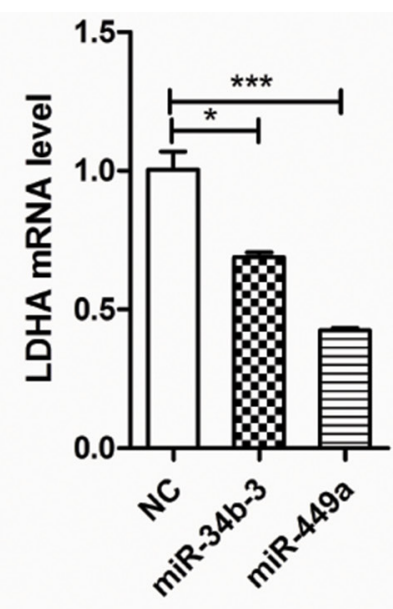

B

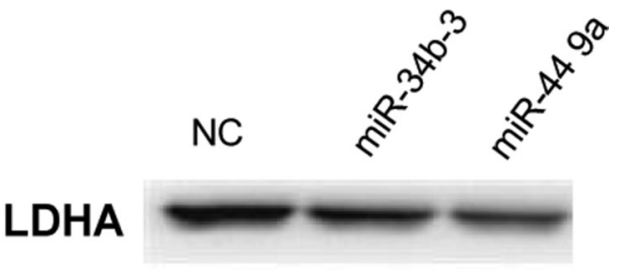

Tublin

C

miR-34b-3

$\operatorname{miR}-449 a$

3' UACCGUCACCUCAAUCACUAAC

II I II I

LDHA 3'UTR 5' ...CUUUUUAUCUGAUCUGUGAUUA

CGUUAGUCGAUUGUUAUGUGACGGU | I | I| || | I I Mutant LDHA 3'UTR 5' ....CUUUUUAUCUGAUCU AAAAAAA.........UGCCACCU T TTTT TT TTT TTTT TTA
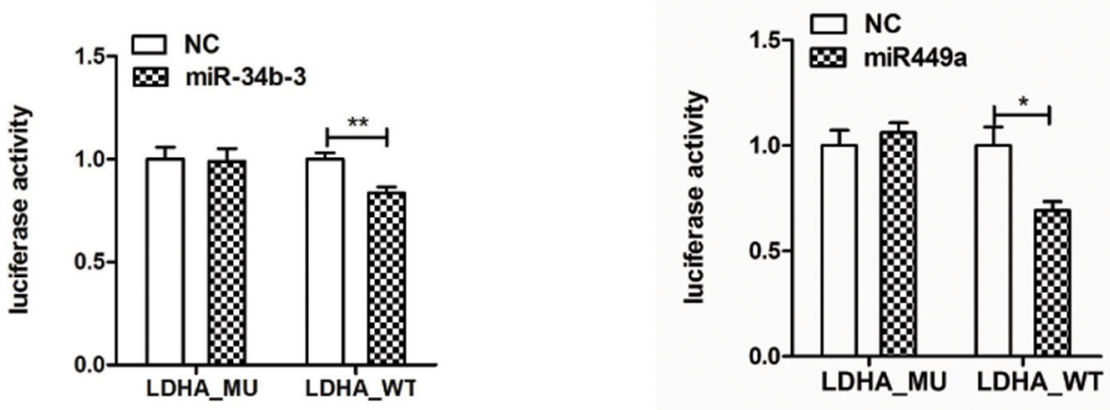

Figure 5: LDHA is a direct target of miR-34b-3 and miR-449a. (A) miR-34b-3 and miR-449a overexpression reduced LDHA mRNA level. Human $\beta$-actin gene was used as an internal control and for normalization of the data. The data are shown as the mean \pm SD $\left({ }^{*} P<0.05 ; * * * P<0.001\right)$. (B) MiR-34b-3 or miR-449a suppressed the protein expression of LDHA. RT-PCR and Western blot analyses of LDHA were performed $48 \mathrm{~h}$ after transfection of the same amount of miR-34b-3, miR-449a mimics or scrambled miRNA (NC). (C) miR-34b-3 and miR-449a reduced the activity of the luciferase reporter with LDHA wild-type 3'UTR in CNE2 cells, but not that carrying mutated 3'UTR. Sequence alignment of miR-34b-3 and miR-449a and LDHA 3'UTR was shown. The experiments were repeated for three times. The data are shown as the mean $\pm \mathrm{SD}(* P<0.05 ; * * P<0.01)$. 
profiles of proteins between miR-34b-3 overexpressing and negative control cells. Over triplicate experiments, we found that 251 proteins were downregulated after ectopic miR-34b-3 expression, among which 15 proteins were commonly verified in three experiments. In the 15 down-regulated proteins, we noted an overrepresentation of proteins clustered in glycolysis metabolism, propanoate and pyruvate metabolism, suggesting the inhibition of glycolysis may be a major consequence of miR-34b-3 activation.
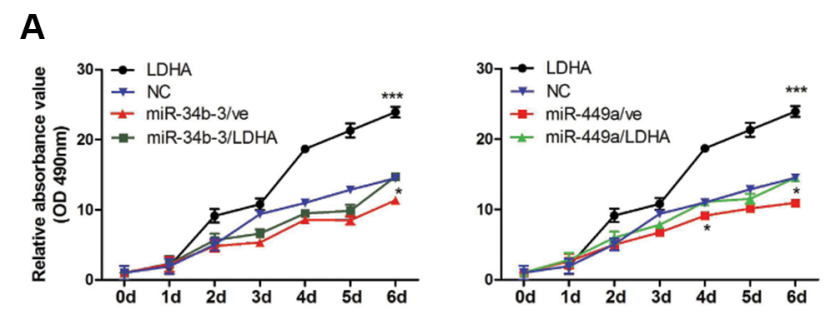

C
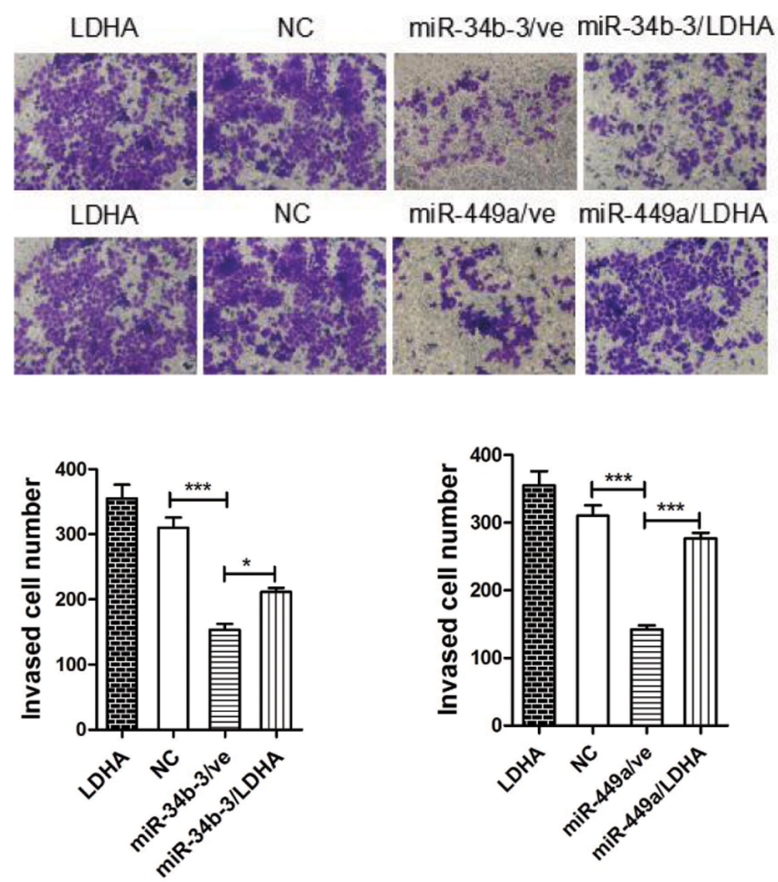

Among 15 down-regulated proteins, only LDHA was predicted by three database including Targetscan, Pictar, and miRanda. LDHA is a key enzyme at glucose to lactate metabolism and catalyzes the inter-conversion of pyruvate and L-lactate, accompanied with NADH and NAD + conversion. In 1956, Warburg observed unusual increase of glycolysis rate in cancer cells even under normal oxygen concentrations [52]. Increased LDHA expression promotes the production of ATP, lipids, fatty acids and nucleotides, which are important materials for

B
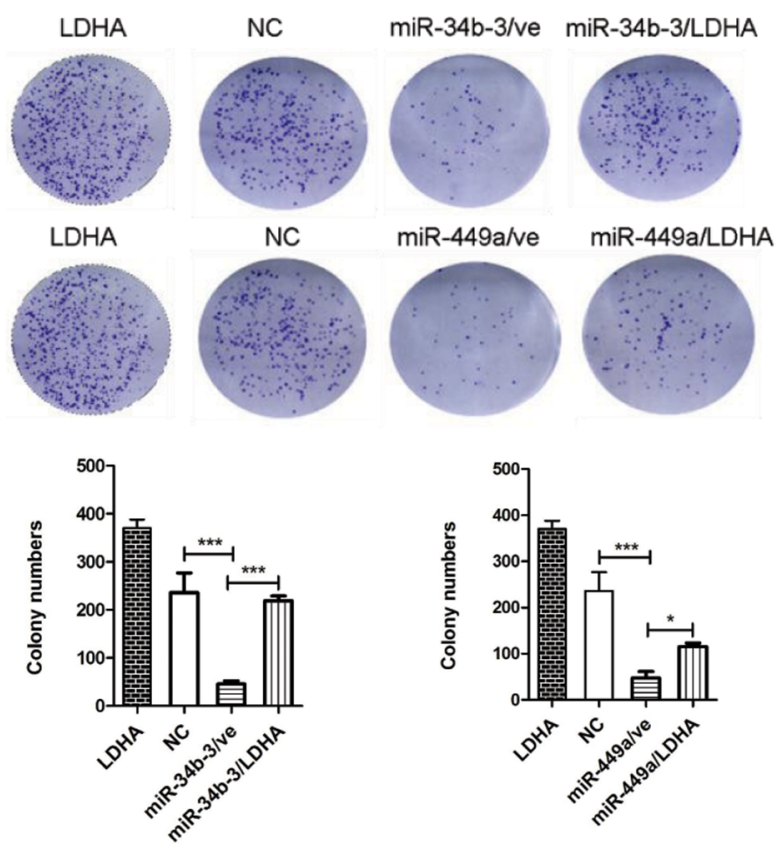

D
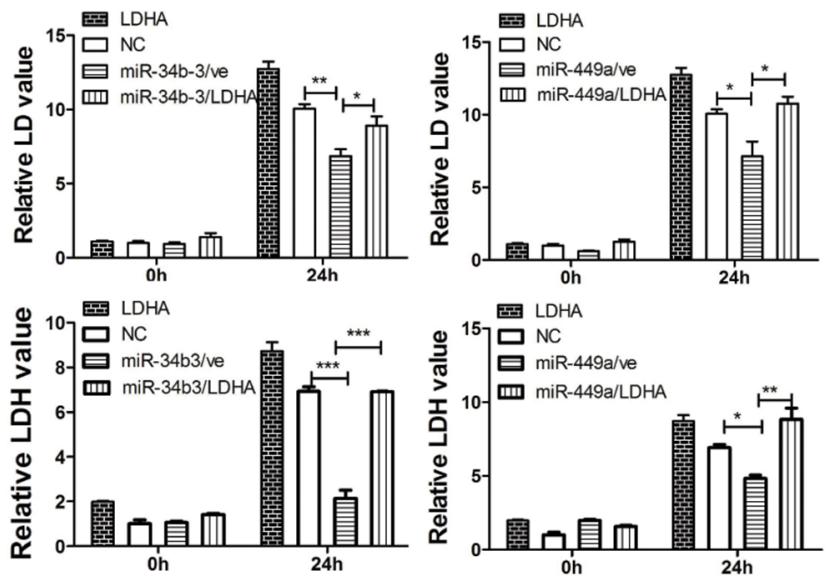

Figure 6: MiR-34b-3 and miR-449a inhibit tumor progression and regulate glycolysis through LDHA in NPC. The transfected CNE2 cells were divided into six groups: Cells cotransfected miR-34b-3 with pENTER-LDHA(miR-34b-3/LDHA) or pENTER3C (miR-34b-3/ve). Cells cotransfected miR-449a mimics with pENTER-LDHA (miR-449a/LDHA) or pENTER-3C (miR-449a/ve). Cells cotransfection of scrambled miRNA and pENTER-3C served as negative control(NC). Cells cotransfection of scrambled miRNA and pENTER-LDHA served as positive control (LDHA). (A) MiR-34b-3 and miR-449a inhibit tumor growth through LDHA. Cell proliferation was measured by MTT assay at the indicated time points. Three independent experiments were performed. The data are shown as the mean $\pm \mathrm{SD}(* P<0.05 ; * * P<0.001)$. (B) MiR-34b-3 and miR-449a inhibit tumor colony formation through LDHA. The colony formation assay was performed after 10 days culture. The graph summarizes the data from three independent experiments $(* P<0.05 ; * * * P<0.001)$. (C) MiR-34b-3 and miR-449a inhibit tumor migration through LDHA. The migrated stained cells were counted and statistical analyses were performed using GraphPad Prism 5 from three independent experiments $\left({ }^{*} P<0.05 ; * * * P<0.001\right)$. (D) MiR-34b-3 and miR-449a regulate glycolysis through LDHA. Cell supernatants at $0 \mathrm{~h}$ and $24 \mathrm{~h}$ after transfection were collected and tested for the levels of lactic acid (LD) and lactic dehydrogenase (LDH). Three independent experiments were performed $(* P<0.05 ; * * P<0.01 ; * * * P<0.001)$. 
tumor progression [53-56]. It was reported that increased serum LDH level is poor prognostic factors for NPC [57]. The EBV-encoded latent membrane protein 1 (LMP1) elevates the LDHA activity and lactate production at NPC cells [58]. Our results imply that LDHA has high expression level in NPC tissues and cells. LDHA overexpression promotes NPC cell growth, invasion and lactic acid production.

LDHA plays an important role in tumor maintenance and invasion, and its over expression is associated with tumor proliferation, angiogenesis, metastasis, and resistance to chemotherapy and radiotherapy [59]. It was recently demonstrated that miR-347a directly target LDHA in colorectal cancer cells [60]. MiR-410 represses LDHA expression and promotes embryonic stem cells (hESC) to differentiate into pancreatic endoderm $(\mathrm{PE})$ in gestational diabetes mellitus treatment [61]. In our study, we showed that miR-34b-3 and miR-449a directly targeted LDHA and LDHA overexpression significantly recovered cell proliferation, LD content and LDH activity in NPC cells following transfection of miR-34b-3 and miR-449a. Our findings suggest that miR-34b-3 and miR-449a suppress NPC progression and metastasis partly through inhibition of LDHA.

In conclusion, we verified that $\mathrm{miR}-34 \mathrm{~b} / \mathrm{c}$ and miR-449a inhibit glycolysis through targeting LDHA in NPC, thereby suppressing the tumor proliferation and progression. These findings will contribute to our understanding of the molecular mechanism by which miR-34b-3 and miR-449a play tumor suppressor roles in the development of NPC and these miRNAs may be potential therapeutic targets to suppress the metabolic reprogramming of NPC cells.

\section{MATERIALS AND METHODS}

\section{Clinical specimens}

Two sets of NPC samples were collected for this study: Set 1, including tissue biopsies of 45 NPC and 10 non-tumor nasopharynx epithelial tissue samples to verify miR-34 and miR-449a expression with qRT-PCR; Set 2, including 20 paraffin-embedded NPC and 4 non-tumor nasopharynx epithelial tissue samples for LDHA detection with IHC. All samples were collected from newly diagnosed NPC patients at the Second Xiangya Hospital (Changsha, China) near two years. All specimens were confirmed by histopathological examination. The patients were informed regarding the sample collection and signed informed consent forms. Collection and use of tissue samples were approved by the Ethical Review Committee of Xiangya Second Hospital. Clinic information was collected from patient medical records and are reported in Supplemental Table S1 and S3.

\section{Cell culture and reagents}

NPC cell lines HNE2, HNE1, CNE2 5-8F, HK1 and C666-1 were cultured in RPMI-1640 medium supplemented with $10 \%$ fetal bovine serum. Immortalized normal nasopharynx epithelial NP69 cells were cultured in RPMI-1640 medium with 10\% FBS and growth factors. The cells were grown at $37^{\circ} \mathrm{C}$ in a humidified atmosphere of $5 \%$ CO2. pENTER-LDHA plasmid containing LDHA ORF with $\mathrm{C}$ terminal Flag and His tag was obtained from ViGene Biosciences (Jinan, China) LDHA primary antibody was obtained from Proteintech (00012244, Wuhan, China). $\alpha$-Tublin primary antibody (212144, Wuhan, China) and HRP labeled secondary antibodies were purchased from Vazyme (Nanjjing, China). MiR-34b-3 mimics (MSY0004676, 5'-CAAUCACUAACUCCACUGCCAU-3'), miR-449a mimics (MSY0001541, 5'-UGGCAGUGUAUUGUU AGCUGGU-3') and scrambled miRNA (a synthesized RNA showing no homology to any human mRNA sequence) were obtained from Qiagen (Valencia, CA, USA). Cells were transfected with miRNA mimics and scrambled miRNA (NC) using Lipofectamine 3000 (Invitrogen), according to the manufacturer's instructions.

\section{RNA extraction and q-RT-PCR}

Total RNA was extracted using Trizol reagent (CWIO, Beijing, China) according to the manufacturer's protocol. The expression level of miR-34b-3 and miR449a was measured by miRNA primer assays and miScript SYBR $^{\circledR}$ Green PCR Kit (Qiagen) in compliance with manufacturer's instructions. Data were normalized to the expression level of small nuclear RNA RNU6B (U6 snRNA). For LDHA expression analysis, $2 \mu \mathrm{g}$ total RNA was reverse transcribed into cDNA with AccuRT Genomic DNA Removal kit (Abm, Milton, ON, Canada). qRT-PCR was performed with EvaGreen 2x qPCR MasterMix (Abm) in the CFX96 Real-time PCR Detection System (Bio-Rad, Hercules, CA, USA) to determine the relative expression levels of target genes. The primer used were as follows: LDHA, 5'-TGGAGTGGAATGAATGTTGC-3' and 5'-ATAGCCCAGGATGTGTAGCC-3'; ACTB ( $\beta$-actin), 5'-TCACCAACTGGGACGACATG-3' and 5'-GTCACCG GAGTCCATCACGAT-3'. ACTB was used as the reference and normalization control. The average of three independent analyses for each gene was calculated.

\section{MTT assay}

Cells were transfected with miR-34b-3, miR-449a mimics or scrambled miRNA (NC) for $24 \mathrm{~h}$, and then seeded in a 96-well plate at a density of $2 \times 10^{3}$ cells/well. 
Changes in cell viability were determined by adding $20 \mu \mathrm{l}$ of 3-(4,5-dimethylthiazole-2-yl)-2,5-diphenyl tetrazolium bromide (MTT) solution $(5 \mathrm{mg} / \mathrm{ml})$ to each well at $0,1,2$, $3,4,5$ and 6-day time points. The plate was incubated at $37^{\circ} \mathrm{C}$ for an additional $4 \mathrm{~h}$. The media was removed and $150 \mu$ of dimethyl sulfoxide was added to each well. The plates were shaken for $10 \mathrm{~min}$ to dissolve MTT formazan crystals. The optical density of each well was determined with a scanning multi-well spectrophotometer at a wavelength of $490 \mathrm{~nm}$. The experiments were repeated three times and six parallel samples were measured each time.

\section{Colony formation assay}

Cells were transfected with miR-34b-3, miR-449a mimics or scrambled miRNA (NC) for $24 \mathrm{~h}$, and then seeded in a 6-well plate in triplicate. After incubation for 9-10 days, plates were gently washed with PBS and stained with $0.1 \%$ of crystal violet. Colonies with over 50 cells were manually counted. Plating efficiency was calculated by dividing the number of colonies formed in the treated group by that in control.

\section{Wound healing assay}

Cells were transfected with miRNA mimics and grown to $90 \%$ confluency in a 6 -well plate. A wound was created using a sterile $10 \mu$ pipette tip followed by washing with D-Hanks to remove detached cells. Cells were then cultured in medium with $2 \%$ serum. Images were captured $0,24,48$ and $72 \mathrm{~h}$ hours after wounding using a microscope (Nikon).

\section{Transwell migration assay}

Before cell seeding, Corning Costar Transwell 24-well plates ( $8 \mu \mathrm{m}$ pores; Corning, NY, USA) were coated with Matrigel (BD) and placed in a cell culture hood for $3 \mathrm{~h}$ at $37^{\circ} \mathrm{C}$. A total of $3 \times 10^{4}$ cells was seeded in the inserts after transfection and cultured in medium with $2 \%$ serum. Normal growth medium was placed in the bottom wells. Cells were then allowed to migrate for $48 \mathrm{~h}$. Migrated cells were fixed with 10\% methanol formaldehyde solution for $20 \mathrm{~min}$ and allowed to air dry. Invasive cells on the lower surface of the membrane were stained by dipping inserts in a staining solution for $20 \mathrm{~min}$ and the stained cells were counted.

\section{Animal experiments}

To confirm the role of miR-34b-3 and miR-449 in the inhibition of cancer cell proliferation in vivo, we performed subcutaneous tumor mouse models. Mice were divided into three groups: miR-34b-3, miR-449a and scrambled miRNA(NC). The transfected CNE2 Cells $\left(1 \times 10^{6}\right)$ were washed once with PBS and subcutaneously injected into nude mice $(n=5)$. The tumors were measured every 4 days, and the growth curves were plotted for each group. The tumor volumes were estimated using the following formula: length $\times$ width $^{2} \times 0.52$. All mice were sacrificed 28 days after inoculation and tumors were isolated and photographed. All photographed tumors were isolated from single experiments at a similar time points. Animal experiments were approved by the Institutional Animal Care and Use Committee of Central South University (Changsha, China).

\section{Lactate production assay and LDH activity assay}

Lactate production and lactic dehydrogenase (LDH) activity were detected using the Lactate Assay Kit (Jiancheng, Nanjing, China) and LDH assay kit (Jiancheng, Nanjing, China), respectively according the manufacturer's instructions. Results were normalized on the basis of the total protein amount of the cells.

\section{Protein digestion and TMT labeling}

Total protein was extracted using a protein extraction buffer consisting of $7 \mathrm{M}$ urea, $2 \mathrm{M}$ Thiourea, $4 \%$ Chaps, $1 \% \mathrm{DTT}$, and $0.5 \%(\mathrm{v} / \mathrm{v})$ protease inhibitor cocktail. The protein concentration was determined by Bradford method using bovine serum albumin as the standard. According to the manufacturer instruction of TMT Isobaric Mass Tag Labeling kit (Thermo, Germany), two samples of miR-34b-3 and negative control (100 $\mu \mathrm{g}$ of each sample) were dissolved in $45 \mu \mathrm{l}$ of $100 \mathrm{mM}$ triethyl ammonium bicarbonate (TEAB), added with $5 \mu 1200 \mathrm{mM}$ TCEP and incubated at $55^{\circ} \mathrm{C}$ for $60 \mathrm{~min} .5 \mu \mathrm{l}$ of $375 \mathrm{mM}$ iodoacetamide (IAA) was added to samples and incubated for $30 \mathrm{~min}$ room temperature in the dark. Protein lysates were precipitated with acetone and digested overnight at $37^{\circ} \mathrm{C}$ with $2.5 \mu \mathrm{l}(1 \mu \mathrm{g} / \mu \mathrm{l})$ of Trypsin. Each $100 \mu \mathrm{g}$ sample was labeled with $41 \mu 1$ of the TMT Label Reagents. The two-plex TMTs Label Reagents were equilibrated to room temperature and each aliquot was resuspended in $41 \mu \mathrm{l}$ of anhydrous acetonitrile. Samples were respectively labeled as follows: TMT-129, NC; TMT-130, miR-34b-3. After reaction for $60 \mathrm{~min}$ at $\mathrm{RT}$, each tube was added with $8 \mu \mathrm{l}$ of 5\% hydroxylamine and incubated for $15 \mathrm{~min}$. Finally, samples were pooled and desalinated for LC-MS/MS analysis.

\section{Anion exchange based fractionation of peptides}

According to the methods of Wisniewski [62], we used different PH Britton and Robinson buffer to separate our samples. A total of $30 \mu \mathrm{g}$ peptide mixture was resuspended in $\mathrm{pH} 11$ buffer, followed by separation on a pipet-based anion exchanger, which was assembled following the Stage Tip principle [63, 64] by stacking 6 layers of Empore Anion Exchange disk (Agilent technologies, 12145012) and 6 layers of Empore SDB 
XC disk (Agilent technologies, 12145010) into a $200 \mu \mathrm{l}$ micropipette tip. For column equilibration and elution of fractions, we used Britton \& Robinson buffer composed of $20 \mathrm{mM}$ acetic acid, $20 \mathrm{mM}$ phosphoric acid, and $20 \mathrm{mM}$ boric acid titrated with $\mathrm{NaOH}$ to the desired $\mathrm{pH}$. After this, $0.1 \mathrm{ml}$ of methanol was add to the tip-column and centrifuged at $3000 \mathrm{rcf} / \mathrm{min}$ for $3 \mathrm{~min}$. Peptides were dissolved in $100 \mu \mathrm{l}$ of PH11 buffer and the flow-through was captured on a StageTip [39] which contained six layers of Anion membrane. Stage tips were washed with $100 \mu 10.1 \% \mathrm{NH} 4 \mathrm{OH}$ in water. Following this, a mixture of $0.1 \% \mathrm{NH} 4 \mathrm{OH}$ and $80 \% \mathrm{ACN}$ was used to transfer the peptides to the substrate StageTip. Finally, fractions were subsequently eluted with buffer solutions of $\mathrm{pH} 11,8,6$, 5,4 , and 3 , respectively.

\section{LC-MS/MS analysis of peptides}

Labeled peptides were analyzed by nano-flow liquid chromatography (Nano-LC)/electrospray ionization (ESI)-tandem MS (MS/MS) using the UltiMate ${ }^{\mathrm{TM}} 3000$ RSLCnano system online coupled to an linear trap quadrupole (LTQ)-Orbitrap Velos Pro mass spectrometer (Thermo Fisher Scientific, Bremen, Germany). Peptide mixtures were dissolved in $0.1 \%$ formic acid. Separation of peptides was carried out as follows: peptide mixtures were loaded onto one C18 pre-columns $(30 \mu \mathrm{m} \times 100$ $\mathrm{mm}$, Thermo Fisher Scientific, Bremen, Germany) equilibrated with $0.1 \%(\mathrm{v} / \mathrm{v})$ fluoroacetic acid, washed and pre-concentrated for $5 \mathrm{~min}$ at a flow rate of $0.3 \mu \mathrm{l} /$ min. The pre-column was then switched in line with a C18 RP nano LC column $(150 \mathrm{~mm} \times 75 \mu \mathrm{m}, 2 \mu \mathrm{m}, 100 \AA$, Thermo Fisher Scientific, Bremen, Germany) and peptides were eluted with a binary system consisting of solvent $\mathrm{A}$ $(0.1 \%$ formic acid in aqueous phase) and solvent $\mathrm{B}(0.08 \%$ formic acid in $80 \% \mathrm{ACN}$ ) with a flow rate of $0.3 \mu \mathrm{l} / \mathrm{min}$. The elution linear gradient was as follow: (a) 3\% B in 0-5 min, (b) 3-40\% B in 5-70 min, (c) $95 \%$ B in 75-80 min, (d) 3\% B in $81-90 \mathrm{~min}$.

The LTQ-Orbitrap Velos Pro instrument was externally calibrated using LTQ Velos ESI Positive Ion Calibration Solution (Thermo Fisher Scientific, Bremen, Germany). The general mass spectrometric parameters were as follows: spray voltage, $2.2 \mathrm{kV}$; capillary voltage, $4.5 \mathrm{~V}$; capillary temperature, $250^{\circ} \mathrm{C}$; tube lens voltage, $100 \mathrm{~V}$. For data-dependent MS/MS analyses, the software XCalibur (Thermo Fisher Scientific, Bremen, Germany) was used. Full scan MS spectra were acquired at a mass resolution of 60,000 (mass range $100-2000 \mathrm{~m} / \mathrm{z}$ ) in the Orbitrap analyzer.

\section{Protein identification and quantification}

Proteins were identified using Proteome Discoverer 1.4 software (Thermo Scientific, Waltham, MA, USA). Thermo raw files were imported and used to conduct a search of the UniProt KB/Swiss-Prot database (release
2014_10). For database searches, mass tolerances were set to $10 \mathrm{ppm}$ and $0.8 \mathrm{Da}$ for precursor and fragment ions, respectively. Peptides identified with false discovery rates $<1 \%(q$-value $<0.01)$ were discarded. A common contaminants database was also included for quality control. Proteins that met the following criteria were considered differentially expressed proteins: i) proteins were identified based on $\geq 2$ peptides with $\geq 95 \%$ confidence and ii) proteins were considered decreased clearly when the protein levels demonstrated an averaged ratio-fold change $\leq 0.8$ in the LC-MS/MS analyses.

\section{Bioinformatics analysis}

For the convenience of gene annotation, corresponding Entrez gene IDs of the proteins were used for further bioinformatics analysis and these genes were predicted whether have matching sequence with miR$34 \mathrm{~b} / \mathrm{c}$ and miR-449a by 3 common databases such as Targetscan, Pictar, and miRanda. To obtain an overview of the biological functions of the proteins whose expression levels displayed an averaged ratio-fold change $\leq 0.8$ difference between the experimental group and control group, we used GSEABASE and GOSTATS of R language software package to analyze the signaling pathways altered after miR-34b-3 restoring.

\section{Immunohistochemistry}

Tissues were fixed with formalin, embedded with paraffin and cut to $4 \mu \mathrm{m}$ serial section. After deparaffinization and rehydration, tissue sections were incubated in proteinase $\mathrm{K}$ for $8 \mathrm{~min}$ at room temperature. Slides were incubated in antigen retrieval buffer $(0.01 \mathrm{M}$ citrate buffer, $\mathrm{PH}$ 6.0) for $30 \mathrm{~min}$, followed by incubation with primary antibody at $4^{\circ} \mathrm{C}$ overnight. After washing with PBS three times, sections were incubated with polymerized HRP and anti-rabbit IgG for $1 \mathrm{~h}$. The slides were washed and developed using 3'-diaminobenzidine hydrochloride as the chromogen, and counterstained with haematoxylin. After dehydration and mounting, the sections were observed and imaged under a microscope (OLYMPUS BX-51, Japan). Two pathologists independently assessed the immuno-histochemistry in the NPC tissue samples who were blinded to the clinicopathological features and the clinical data. LDHA expression were evaluated in a semiquantitative manner, where by the levels of expression are represented as the percentage of positive cells and the intensity of staining $[$ Hscore $=1 \times(\%$ weak $)+2 \times(\%$ moderate $)+3 \times$ ( $\%$ intense) in a range between 0 and 300].

\section{Western blot analysis}

The proteins were extracted using RadioImmunoprecipitation Assay Buffer (RIPA buffer, Beyotime Biotechnology, Haimen, China). Proteins were 
quantified using the $\mathrm{BCA}^{\mathrm{TM}}$ Protein Assay Kit (Thermo Fisher Scientific). Equal amount of proteins $(50 \mu \mathrm{g})$ were separated by $12 \%$ sodium dodecyl sulfate-polyacrylamide gel electrophoresis and transferred onto a PVDF membrane. After being blocked with 5\% nonfat milk in TBS Tween 20 (TBST; 25 mM Tris pH 7.5, $150 \mathrm{mM} \mathrm{NaCl}$, $0.1 \%$ Tween 20 ) for $1 \mathrm{~h}$ at room temperature, membranes were incubated with primary antibodies in 5\% nonfat milk in TBST overnight at $4^{\circ} \mathrm{C}$. After washing three times with TBST, membranes were then incubated with horseradish peroxidase-labeled secondary antibody for $1 \mathrm{~h}$ at room temperature. The signal was visualized using an ECL detection reagent (Vazyme, Nanjing, China) and quantified by using the BioRad ChemiDoc XRS system.

\section{Luciferase reporter assay}

For miRNA target validation, the 3'UTR of LDHA was PCR-amplified using human genomic DNA and cloned into the downstream of pGL3.0 control reporter vector (Promega). Constructs containing mutated miRNA binding sites in 3'UTR were generated using the QuikChange site-directed mutagenesis kit (Stratagene). CNE2 cells were cultured in 24-well plates $\left(1 \times 10^{5}\right.$ cells per well $)$ and co-transfected with $50 \mathrm{nM}$ miRNA mimics, $1 \mu \mathrm{g}$ firefly luciferase reporter containing the 3'UTR and $100 \mathrm{ng}$ Renilla luciferase reporter. After $48 \mathrm{~h}$, the luciferase activity was measured using the Dual-Glo luciferase ${ }^{\circledR}$ reporter assay system (Promega). Data were normalized against values of co-transfected Renilla luciferase. Cells transfected with scrambled miRNA (a synthesized RNA showing no homology to any human mRNA sequence) served as negative controls. All experiments were performed three times.

\section{Statistical analysis}

Statistical calculations were performed in GraphPad Prism5 software. Student's $t$-tests were used to evaluate significant difference between any two groups of data. Oneway ANOVA was used when there are more than two groups. All data are represented as mean \pm standard deviation (SD). Difference was considered significant if $p<0.05$.

\section{CONFLICTS OF INTEREST}

The authors declare that there are no conflicts of interest in this work.

\section{FUNDING SUPPORTS}

This work was supported by National Natural Science Foundation of China (No. 81000882); The Hunan Province Natural Sciences Foundation of China (No. 10JJ7003); The Central South University teacher's fund (No.2014JSJJ032); The Open-End Fund for the Valuable and Precision Instruments of Central South University
(No.CSUZC2014044) and The student innovation project of Central south university (2014zzts300, 2204120506,201510533361).

\section{REFERENCES}

1. Yu MC, Yuan J. Epidemiology of nasopharyngeal carcinoma. Semin Cancer Biol. 2002; 12:421-429.

2. Hui EP, Leung SF, Au JS, Zee B, Tung S, Chua D, Sze WM, Law CK, Leung TW, Chan AT. Lung metastasis alone in nasopharyngeal carcinoma : a relatively favorable prognostic group. Cancer. 2004; 101:300-306.

3. Deng M, Tang H, Zhou Y, Zhou M, Xiong W, Zheng Y, Ye Q, Zeng X, Liao Q, Guo X, Li X, Ma J, Li G. miR-216b suppresses tumor growth and invasion by targeting KRAS in nasopharyngeal carcinoma. J Cell Sci. 2011; 124:2997-3005.

4. Alajez NM, Lenarduzzi M, Ito E, Hui AB, Shi W, Bruce J, Yue S, Huang SH, Xu W, Waldron J, O'Sullivan B, Liu FF. MiR-218 suppresses nasopharyngeal cancer progression through downregulation of survivin and the SLIT2-ROBO1 pathway. Cancer Research. 2011; 71:2381-2391.

5. Zhang L, Deng T, Li X, Liu H, Zhou H, Ma J, Wu M, Zhou M, Shen S, Li X, Niu Z, Zhang W, Shi L, et al. microRNA-141 is involved in a nasopharyngeal carcinoma-related genes network. Carcinogenesis. 2010; 31:559-566.

6. Xu YF, Mao YP, Li YQ, Ren XY, He QM, Tang X, Sun Y, Liu N, Ma J. MicroRNA-93 promotes cell growth and invasion in nasopharyngeal carcinoma by targeting disabled homolog-2. Cancer Lett. 2015; 363:146-155.

7. Luo Z, Dai Y, Zhang L, Jiang C, Li Z, Yang J, McCarthy JB, She X, Zhang W, Ma J, Xiong W, Wu M, Lu J, et al. miR-18a promotes malignant progression by impairing microRNA biogenesis in nasopharyngeal carcinoma. Carcinogenesis. 2013; 34:415-425.

8. Baetel DP. MicroRNAs: genomics, biogenesis, mechanism, and function. Cell. 2004; 116:281-297.

9. Lu J, Luo H, Liu X, Peng Y, Zhang B, Wang L, Xu X, Peng X, Li G, Tian W, He M, Kung H, Li X. miR-9 targets CXCR4 and functions as a potential tumor suppressor in nasopharyngeal carcinoma. Carcinogenesis. 2014; 35:554-563.

10. Si ML, Zhu S, Wu H, Lu Z, Wu F, YY M. miR-21-mediated tumor growth. Oncogene. 2007; 26:2799-2803.

11. Kim NH, Cha YH, Kang SE, Lee Y, Lee I, Cha SY, Ryu JK, Na JM, Park C, Yoon HG, Park GJ, Yook JI, Kim HS. p53 regulates nuclear GSK-3 levels through miR-34-mediated Axin2 suppression in colorectal cancer cells. Cell Cycle. 2013; 12:1578-1587.

12. Cimmino A, Calin GA, Fabbri M, Iorio MV, Ferracin M, Shimizu M, Wojcik SE, Aqeilan RI, Zupo S, Dono M, Rassenti L, Alder H, Volinia S, et al. miR-15 and miR-16 induce apoptosis by targeting BCL2. Proc Natl Acad Sci U S A. 2005; 102:13944-13949.

13. Gregory PA, Bert AG, Paterson EL, Barry SC, Tsykin A, Farshid G, Vadas MA, Khew-Goodall Y, Goodall GJ. 
The miR-200 family and miR-205 regulate epithelial to mesenchymal transition by targeting ZEB1 and SIP1. Nat Cell Biol. 2008; 10:593-601.

14. Luo Z, Zhang L, Li Z, Li X, Li G, Yu H, Jiang C, Dai Y, Guo X, Xiang J, Li G. An in silicoanalysis of dynamic changes in microRNA expression profiles in stepwise development of nasopharyngeal carcinoma. BMC Med Genomics. 2012; 5:3.

15. Li T, Chen JX, Fu XP, Yang S, Zhang Z, Chen KhH YL. microRNA expression profiling of nasopharyngeal carcinoma. Oncol Rep. 2011; 25:1353-1363.

16. Sengupta S, den Boon JA, Chen IH, Newton MA, Stanhope SA, Cheng YJ, Chen CJ, Hildesheim A, Sugden B, Ahlquist P. MicroRNA 29c is down-regulated in nasopharyngeal carcinomas, up-regulating mRNAs encoding extracellular matrix proteins. Proc Natl Acad Sci U S A. 2008; 105:5874-5878.

17. Chen HC, Chen GH, Chen YH, Liao WL, Liu CY, Chang KP, Chang YS, Chen SJ. MicroRNA deregulation and pathway alterations in nasopharyngeal carcinoma. Br J Cancer. 2009; 100:1002-1011.

18. Wan XX, Yi H, Qu JQ, He QY, Xiao ZQ. Integrated analysis of the differential cellular and EBV miRNA expression profiles in microdissected nasopharyngeal carcinoma and non-cancerous nasopharyngeal tissues. Oncol Rep. 2015; 34:2585-2601.

19. Chang TC, Wentzel EA, Kent OA, Ramachandran K, Mullendore M, Lee KH, Feldmann G, Yamakuchi M, Ferlito M, Lowenstein CJ, Arking DE, Beer MA, Maitra A, et al. Transactivation of miR-34a by $\mathrm{p} 53$ broadly influences gene expression and promotes apoptosis. Mol Cell. 2007; 26:745-752.

20. Bommer GT, Gerin I, Feng Y, Kaczorowski AJ, Kuick R, Love RE, Zhai Y, Giordano TJ, Qin ZS, Moore BB, MacDougald OA, Cho KR, Fearon ER. p53-mediated activation of miRNA34 candidate tumor-suppressor genes. Curr Biol. 2007; 17:1298-1307.

21. He L, He X, Lim LP, de Stanchina E, Xuan Z, Liang Y, Xue W, Zender L, Magnus J, Ridzon D, Jackson AL, Linsley PS, Chen C, et al. A microRNA component of the p53 tumour suppressor network. Nature. 2007; 447:1130-1134.

22. Hermeking $\mathrm{H}$. The miR-34 family in cancer and apoptosis. Cell Death Differ. 2010; 17:193-199.

23. He X, He L, GJ H. The guardian's little helper: microRNAs in the p53 tumor suppressor network. Cancer Research. 2007; 67:11099-11101.

24. Choi YJ, Lin CP, Ho JJ, He X, Okada N, Bu P, Zhong Y, Kim SY, Bennett MJ, Chen C, Ozturk A, Hicks GG, Hannon GJ, He L. miR-34 miRNAs provide a barrier for somatic cell reprogramming. Nat Cell Biol. 2011; 13: 1353-1360.

25. Marcet B, Chevalier B, Luxardi G, Coraux C, Zaragosi LE, Cibois M, Robbe-Sermesant K, Jolly T, Cardinaud B, Moreilhon C, Giovannini-Chami L, Nawrocki-Raby B, Birembaut $\mathrm{P}$, et al. Control of vertebrate multiciliogenesis by miR-449 through direct repression of the Delta/Notch pathway. Nat Cell Biol. 2011; 13:693-699.

26. Niu M, Gao D, Wen Q, Wei P, Pan S, Shuai C, Ma H, Xiang J, Li Z, Fan S, Li G, Peng S. MiR-29c regulates the expression of miR-34c and miR-449a by targeting DNA methyltransferase $3 \mathrm{a}$ and $3 \mathrm{~b}$ in nasopharyngeal carcinoma. BMC Cancer. 2016; 16:218.

27. Bao J, Li D, Wang L, Wu J, Hu Y, Wang Z, Chen Y, Cao X, Jiang C, Yan W, Xu C. MicroRNA-449 and microRNA$34 \mathrm{~b} / \mathrm{c}$ function redundantly in murine testes by targeting E2F transcription factor-retinoblastoma protein (E2F-pRb) pathway. J Biol Chem. 2012; 287:21686-21698.

28. Yuan S, Tang C, Zhang Y, Wu J, Bao J, Zheng H, Xu C, Yan W. mir-34b/c and mir-449a/b/c are required for spermatogenesis, but not for the first cleavage division in mice. Biol Open. 2015; 4:212-223.

29. Shi M, Cui J, Du J, Wei D, Jia Z, Zhang J, Zhu Z, Gao Y, Xie K. A novel KLF4/LDHA signaling pathway regulates aerobic glycolysis in and progression of pancreatic cancer. Clin Cancer Res. 2014; 20:4370-4380.

30. Cui J, Shi M, Xie D, Wei D, Jia Z, Zheng S, Gao Y, Huang S, Xie K. FOXM1 promotes the warburg effect and pancreatic cancer progression via transactivation of LDHA expression. Clin Cancer Res. 2014; 20:2595-2606.

31. Rong Y, Wu W, Ni X, Kuang T, Jin D, Wang D, Lou W. Lactate dehydrogenase A is overexpressed in pancreatic cancer and promotes the growth of pancreatic cancer cells. Tumour Biol. 2013; 34:1523-1530.

32. Girgis H, Masui O, White NM, Scorilas A, Rotondo F, Seivwright A, Gabril M, Filter ER, Girgis AH, Bjarnason GA, Jewett MA, Evans A, Al-Haddad S, et al. Lactate dehydrogenase $\mathrm{A}$ is a potential prognostic marker in clear cell renal cell carcinoma. Mol Cancer. 2014; 13:101.

33. Yao F, Zhao T, Zhong C, Zhu J, Zhao H. LDHA is necessary for the tumorigenicity of esophageal squamous cell carcinoma. Tumour Biol. 2013; 34:25-31.

34. Cai Z, Zhao JS, Li JJ, Peng DN, Wang XY, Chen TL, Qiu YP, Chen PP, Li WJ, Xu LY, Li EM, Tam JP, Qi RZ, et al. A combined proteomics and metabolomics profiling of gastric cardia cancer reveals characteristic dysregulations in glucose metabolism. Mol Cell Proteomics. 2010; 9:2617-2628.

35. White NM, Masui O, Desouza LV, Krakovska O, Metias S, Romaschin AD, Honey RJ, Stewart R, Pace K, Lee J, Jewett MA, Bjarnason GA, Siu KW, et al. Quantitative proteomic analysis reveals potential diagnostic markers and pathways involved in pathogenesis of renal cell carcinoma. Oncotarget. 2014; 5:506-518. doi: 10.18632/ oncotarget.1529.

36. Lo AK, Dawson CW, Young LS, Ko CW, Hau PM, Lo KW. Activation of the FGFR1 signalling pathway by the EpsteinBarr virus-encoded LMP1 promotes aerobic glycolysis and transformation of human nasopharyngeal epithelial cells. J Pathol. 2015; 237:238-48.

37. Chung FZ, Tsujibo H, Bhattacharyya U, Sharief FS, LI SS. Genomic organization of human lactate dehydrogenase-A gene. Biochem J. 1985; 231:537-541. 
38. Yang Y, Su D, Zhao L, Zhang D, Xu J, Wan J, Fan S, Chen M. Different effects of LDH-A inhibition by oxamate in non-small cell lung cancer cells. Oncotarget. 2014; 5:11886-11896. doi: 10.18632/oncotarget.2620.

39. Mirebeau-Prunier D, Le Pennec S, Jacques C, Fontaine JF, Gueguen N, Boutet-Bouzamondo N, Donnart A, MalthieryY, Savagner F. Estrogen-related receptor alpha modulates lactate dehydrogenase activity in thyroid tumors. PLOS One. 2013; 8:e58683.

40. Zhao D, Zou SW, Liu Y, Zhou X, Mo Y, Wang P, Xu YH, Dong B, Xiong Y, Lei QY, Guan KL. Lysine-5 acetylation negatively regulates lactate dehydrogenase $\mathrm{A}$ and is decreased in pancreatic cancer. Cancer Cell. 2013; 23:464-476.

41. Wei Z, Zeng X, Xu J, Duan X, Xie Y. Prognostic value of pretreatment serum levels of lactate dehydrogenase in nonmetastatic nasopharyngeal carcinoma: single-site analysis of 601 patients in a highly endemic area. Onco Targets Ther. 2014; 7:739-749.

42. Jin Y, Ye X, Shao L, Lin BC, He CX, Zhang BB, Zhang YP. Serum lactic dehydrogenase strongly predicts survival in metastatic nasopharyngeal carcinoma treated with palliative chemotherapy. Eur J Cancer. 2013; 49:1619-1626

43. Zhou GQ, Ren XY, Mao YP, Chen L, Sun Y, Liu LZ, Li L, Lin AH, Mai HQ, Ma J. Prognostic implications of dynamic serum lactate dehydrogenase assessments in nasopharyngeal carcinoma patients treated with intensitymodulated radiotherapy. Sci Rep. 2016; 6:22326.

44. Zhai X, Yang Y, Wan J, Zhu R, Wu Y. Inhibition of LDH-A by oxamate induces $\mathrm{G} 2 / \mathrm{M}$ arrest, apoptosis and increases radiosensitivity in nasopharyngeal carcinoma cells. Oncol Rep. 2013; 30:2983-2991.

45. Li X, Lu W, Hu Y, Wen S, Qian C, Wu W, Huang P. Effective inhibition of nasopharyngeal carcinoma in vitro and in vivo by targeting glycolysis with oxamate. Int J Oncol. 2013; 43:1710-8.

46. Wang L, Yu J, Xu J, Zheng C, Li X, Du J. The analysis of microRNA-34 family expression in human cancer studies comparing cancer tissues with corresponding pericarcinous tissues. Gene. 2015; 554:1-8.

47. Hsu SD, Chu CH, Tsou AP, Chen SJ, Chen HC, Hsu PW, Wong YH, Chen YH, Chen GH, Huang HD. miRNAMap 2.0: genomic maps of microRNAs in metazoan genomes. Nucleic Acids Res. 2008; 36:D165-D169.

48. Bader AG. miR-34 - a microRNA replacement therapy is headed to the clinic. Front Genet. 2012; 3:120.

49. Wu J, Bao J, Kim M, Yuan S, Tang C, Zheng H, Mastick GS, Xu C, Yan W. Two miRNA clusters, miR-34b/c and miR-449, are essential for normal brain development, motile ciliogenesis, and spermatogenesis. Proc Natl Acad Sci U S A. 2014; 111:E2851-E2857.

50. Dayon L, Hainard A, Licker V, Turck N, Kuhn K, Hochstrasser DF, Burkhard PR, Sanchez JC. Relative quantification of proteins in human cerebrospinal fluids by MS/MS using 6-plex isobaric tags. Anal Chem. 2008; 80:2921-2931.
51. Thompson A, Schafer J, Kuhn K, Kienle S, Schwarz J, Schmidt G, Neumann T, Johnstone R, Mohammed AK, Hamon C. Tandem mass tags: a novel quantification strategy for comparative analysis of complex protein mixtures by MS/MS. Anal Chem. 2003; 75:1895-1904.

52. Warbuge O. On the origin of cancer cells. Science. 1956; 123:309-14.

53. Bui T, Thompson CB. Cancer's sweet tooth. Cancer Cell. 2006; 9:419-420.

54. Vander HM, Cantley LC, Thompson CB. Understanding the Warburg effect: the metabolic requirements of cell proliferation. Science. 2009; 324:1029-1033.

55. DeBerardinis RJ, Sayed N, Ditsworth D, Thompson CB. Brick by brick: metabolism and tumor cell growth. Curr Opin Genet Dev. 2008; 18:54-61.

56. Valvona CJ, Fillmore HL, Nunn PB, Pilkington GJ. The Regulation and Function of Lactate Dehydrogenase A: Therapeutic Potential in Brain Tumor. Brain Pathol. 2016; 26:3-17.

57. Turen S, Ozyar E, Altundag K, Gullu I, Atahan IL. Serum lactate dehydrogenase level is a prognostic factor in patients with locoregionally advanced nasopharyngeal carcinoma treated with chemoradiotherapy. Cancer Invest. 2007; 25:315-321.

58. Lo AK, Dawson CW, Young LS, Ko CW, Hau PM, Lo KW. Activation of the FGFR1 signalling pathway by the EpsteinBarr virus-encoded LMP1 promotes aerobic glycolysis and transformation of human nasopharyngeal epithelial cells. J Pathol. 2015; 237:238-248.

59. Miao P, Sheng S, Sun X, Liu J, Huang G. Lactate dehydrogenase A in cancer: a promising target for diagnosis and therapy. Iubmb Life. 2013; 65:904-910.

60. Wang J, Wang H, Liu A, Fang C, Hao J, Wang Z. Lactate dehydrogenase A negatively regulated by miRNAs promotes aerobic glycolysis and is increased in colorectal cancer. Oncotarget. 2015; 6:19456-19468. doi: 10.18632/ oncotarget.3318.

61. Mi Y, Guo N, He T, Ji J, Li Z, Huang P. miR-410 enhanced hESC-derived pancreatic endoderm transplant to alleviate gestational diabetes mellitus. J Mol Endocrinol. 2015; 55:219-229.

62. Wisniewski JR, Zougman A, Mann M. Combination of FASP, StageTip-based fractionation allows in-depth analysis of the hippocampal membrane proteome. J Proteome Res. 2009; 8:5674-5678.

63. Rappsilber J, Ishihama Y, Mann M. Stop and go extraction tips for matrix-assisted laser desorption/ionization, nanoelectrospray, and LC/MS sample pretreatment in proteomics. Anal Chem. 2003; 75:663-670.

64. Ishihama Y, Rappsilber J, Mannon M. Modular stop and go extraction tips with stacked disks for parallel and multidimensional Peptide fractionation in proteomics. J Proteome Res. 2006; 5:988-994. 